\title{
Aldosterone to Renin Activity Ratio Measurement
}

National Cancer Institute

\section{Source}

National Cancer Institute. Aldosterone to Renin Activity Ratio Measurement. NCI

Thesaurus. Code C124338.

The determination of the ratio of the aldosterone compared to renin activity present in a sample. The measurement may be expressed as a ratio or percentage. 